Article

\title{
Effective Gold Biosorption by Electrospun and Electrosprayed Bio-Composites with Immobilized Lysinibacillus sphaericus CBAM5
}

\author{
Carolina Páez-Vélez ${ }^{1}$, J. L. Castro-Mayorga ${ }^{2}$ and Jenny Dussán ${ }^{1, *(\mathbb{D})}$ \\ 1 Microbiological Research Center (CIMIC), Department of Biological Sciences, Universidad de Los Andes, \\ Bogotá 111711, Colombia; c.paez1660@uniandes.edu.co \\ 2 Nanobiotechnology and Applied Microbiology (NANOBIOT), Department of Biological Sciences, \\ Universidad de Los Andes, Bogotá 111711, Colombia; jl.castrom@uniandes.edu.co \\ * Correspondence: jdussan@uniandes.edu.co
}

Received: 16 December 2019; Accepted: 1 February 2020; Published: 26 February 2020

\begin{abstract}
Electro-hydrodynamic processing, comprising electrospinning and electrospraying techniques, is a novel technology used in the production of nano- and sub-micro-scale materials with specific properties suitable for environmental remediation processes. Polycaprolactone (PCL) micro-fibrous mats and alginate microcapsules were produced using electrospinning and electrospraying techniques respectively, and Lysinibacillus sphaericus CBAM5, a bacterium capable of metal removal by adsorption and accumulation inside the cell, was immobilized in these matrices. The polymeric structure was able to protect and maintain cell viability and the bio-composite materials were used to capture gold from synthetic water samples. The micro-fibrous membranes with immobilized bacteria were able to remove $93 \%$ of the gold after $120 \mathrm{~h}$ of inclusion in the aqueous medium. Using a filtration system, an efficiency of $64 \%$ was obtained for the removal of the precious metal after 10 cycles of filtration ( $2 \mathrm{~h}$ of exposure to the gold solution). In contrast, the microencapsulated L. sphaericus CBAM5 captured $64 \%$ of the gold after $4 \mathrm{~h}$ of the assay. Thus, both micro-structured matrices were suitable for the immobilization and protection of L. sphaericus CBAM5 and they showed high efficiencies of gold biosorption. Hence, these bio-composite materials could be used to concentrate gold from industrial wastewaters.
\end{abstract}

Keywords: gold; electrospinning; electrospraying; polycaprolactone; alginate; Lysinibacillus sphaericus CBAM5

\section{Introduction}

One of the major challenges for humanity nowadays is to provide clean water for the entire global societies. Population growth, contamination of water sources by industrial activities, and droughts among other conditions, hamper efficient water supply in modern communities [1]. Mining and metallurgical operations are responsible for a great proportion of water contamination by metal ions, a type of pollutant that requires complex technologies for its removal from water bodies [2].

Some of the techniques used currently to remove metals include chemical precipitation, sorption, coagulation, and oxidation/reduction, among others [2]. Sorption seems to work as a good alternative in the capture of metal ions due to its low cost, simple operation, its lack of byproducts, and the regeneration of the starting materials [2]. Sorption also makes it possible to recover and recycle metal ions from wastewaters with interesting properties for industrial applications. Gold is a clear example of this. This precious metal is characterized by its slow corrosion, high conductivity, and its nanoparticles are currently being implemented in the electronic, biomedical, and pharmaceutical industries [3]. 
The past two decades have seen rapid advances in the field of nanotechnology and several new applications have emerged from these studies. The obtained nanomaterials are characterized for having large surface areas, stability, adequate mechanical properties, and low toxicity, among others [2]. Due to these specific properties, several nanomaterials have been used in environmental sciences as an alternative in remediation processes [1]. Particularly in the field of water treatment, the removal of pollutants is a great challenge and a current problem due to increased industrial activity, such as mining and metallurgy [2]. There has therefore been an increment in the use of nanostructured components because they have shown several advantages over traditional water treatment techniques as a result of their large surface areas and reactivity [1].

In recent years, a top-down technique called electro-hydrodynamic processing (EHP) has been used to manufacture nanomaterials. It consists in the injection of a polymer solution exposed to a high voltage which creates a fine, elongated jet that determines the diameter of the electrospun fibers or electrosprayed capsules formed [4]. This is a simple and effective technique with applications at the industrial level, given that it can be scaled-up [5].

In the case of water treatment, adsorption of pollutants has shown considerable advantages, thus several nanomaterials have been used for such applications [6]. Nano-adsorbent materials from organic polymers obtained by EHP are known to have large surface areas and high porosity that allow the capture of heavy metals from aqueous media [5]. Such nano-adsorbents can be obtained from polymers like polycaprolactone (PCL) and sodium alginate and they are biodegradable, easy to manipulate, and biocompatible, among others $[7,8]$. These polymers have also been used as immobilization matrices for bacteria with metabolic potential for remediation processes in the environment. These types of bio-composite materials have been studied for the removal of textile dyes, heavy metals, and other water pollutants [9-11].

Lysinibacillus sphaericus is a Gram-positive bacterium that has been extensively studied for its ability to resist and capture metals such as uranium, $\mathrm{Pb}(\mathrm{II}), \mathrm{Cr}(\mathrm{IV}), \mathrm{Cd}(\mathrm{II}), \mathrm{Hg}$ (II), and $\mathrm{Au}(\mathrm{III})$ [12-16]. It is known to have a surface layer (S-layer) protein, which is a porous lattice that protects it and acts as an ion trap. The strain L. sphaericus CBAM5 has shown a great potential to capture several metal ions like gold and mercury [15-17]. A study of its genomic sequence has shown that it possesses several coding regions for S-Layer proteins and it presents heavy metal efflux pumps that help the cell to resist high concentrations of metal ions $[13,18]$.

Accordingly, the aim of this study was to synthesize and characterize micro-fibrous membranes of PCL and microcapsules of alginate. The immobilization of living cells of L. sphaericus CBAM5 in these two types of materials was performed. Additionally, the gold biosorption efficiency of these bio-composite materials was determined by using different methods of exposure to water samples containing the metal ion.

\section{Materials and Methods}

\subsection{Bacterial Growth and Media}

The selected strain, L. sphaericus CBAM5, was incubated in nutrient agar (OXOID) for $24 \mathrm{~h}$ at $30{ }^{\circ} \mathrm{C}$. The biomass was then collected and resuspended in minimum salt medium (MSM). This medium contains: $\mathrm{KH}_{2} \mathrm{PO}_{4} 0.5 \mathrm{~g} / \mathrm{L}, \mathrm{NH}_{4} \mathrm{Cl} 1 \mathrm{~g} / \mathrm{L}, \mathrm{Na}_{2} \mathrm{SO}_{4} 2 \mathrm{~g} / \mathrm{L}, \mathrm{KNO}_{3} 2 \mathrm{~g} / \mathrm{L}, \mathrm{CaCl}_{2} 0.001 \mathrm{~g} / \mathrm{L}, \mathrm{FeSO}_{4} 0.0004 \mathrm{~g} / \mathrm{L}$, $\mathrm{MgSO}_{4} \cdot 7 \mathrm{H}_{2} \mathrm{O} 1 \mathrm{~g} / \mathrm{L}$, and sodium acetate $5 \mathrm{~g} / \mathrm{L}$. The resuspended bacteria had a concentration of approximately $10^{8}-10^{9}$ colony-forming units $(\mathrm{CFU}) / \mathrm{mL}$ and was then used for the microencapsulation and immobilization assays.

\subsection{Production of Bio-Composite Microstructures}

All the sub-micro-structured materials were synthesized using an EHP machine (NANOFIB1000) with a flow pump BYZ-810D, as shown in Figure 1, manufactured and commercialized by Qubitextp (Bogotá, Colombia). 


\subsubsection{Electrospinning of Polycaprolactone (PCL) Micro-Fibrous Mats}

The PCL solution was prepared by dissolving $8 \%$ (wt./wt.) of polymer in a chloroform/1-butanol 75:25 (wt/wt) mixture, both reagent grades, at room temperature and with magnetic stirring. The PCL solution was electrospun for $3 \mathrm{~h}$ using an EHP machine (Figure 1a). The solutions were then processed at room temperature under a constant flow of $10 \mathrm{~mL} / \mathrm{h}$ using an 18-gauge injector, scanning vertically onto the metallic cylindrical collector covered with aluminum foil with an oscillatory movement at $1600 \mathrm{rpm}$. A dual polarization added voltage of $9.8 \mathrm{kV}$ per single emitter and a tip-to-collector distance of $12 \mathrm{~cm}$ were used.

The PCL micro-fibrous mat obtained was dried for $24 \mathrm{~h}$ in a desiccator and sterilized under UV light for $40 \mathrm{~min}$ on each side.

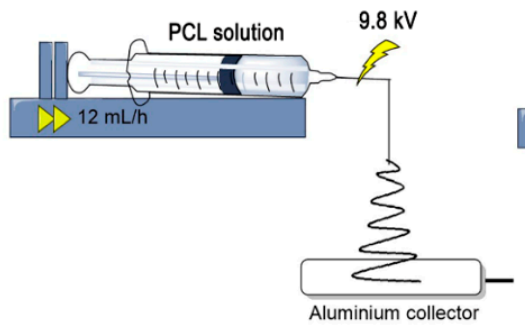

(a)

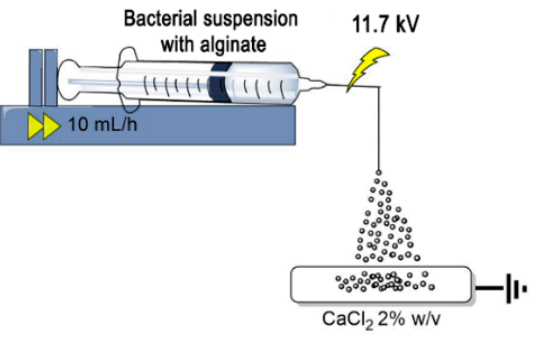

(b)

Figure 1. Representation of the electrohydrodynamic processing used to obtain (a) micro-fibrous mats of Polycaprolactone (PCL) and (b) microcapsules of alginate with L. sphaericus CBAM5.

\subsubsection{Immobilization by Adhesion of L. sphaericus CBAM5 in PCL Micro-Fibrous Mats}

Six pieces of $5.5 \times 6 \mathrm{~cm}$ and average weight of $0.13 \pm 0.03 \mathrm{~g}$ of PCL membranes were placed in $50 \mathrm{~mL}$ flasks with $30 \mathrm{~mL}$ of a L. sphaericus CBAM5 suspension with a concentration of $1.02 \times 10^{9} \mathrm{CFU} / \mathrm{mL}$ in saline solution $(0.85 \%)$. The flasks were incubated at $30{ }^{\circ} \mathrm{C}, 150 \mathrm{rpm}$ for $5 \mathrm{~h}$. The membranes were then washed twice with sterile saline solution $(0.85 \%)$ to remove non-immobilized cells.

Bacterial immobilization was confirmed by scanning electron microscopy (SEM) analysis and a detachment protocol was used to estimate the bacterial concentration immobilized in the membranes.

The detachment protocol was made as previously reported [11]. Firstly, three membranes were transferred to flasks containing $15 \mathrm{~mL}$ of sterile saline solution $(0.85 \%)$ and these were vortexed for $30 \mathrm{~s}$. Then, sonication was performed at $40 \mathrm{kHz}$ and $4{ }^{\circ} \mathrm{C}$ in a Branson 2800 Ultrasonic cleaner during 2 cycles of $1 \mathrm{~min}$ sonication and $30 \mathrm{~s}$ rest for a total of $10 \mathrm{~min}$ of sonication. After sonication, the membranes were vortexed for $1 \mathrm{~min}$ and between each cycle, fresh saline solution $(0.85 \%)$ was used. Standard serial 10-fold dilutions were inoculated $(10 \mu \mathrm{L})$ in nutrient agar and incubated for $24 \mathrm{~h}$ at $30{ }^{\circ} \mathrm{C}$ for the drop plate count method [19].

\subsubsection{Microencapsulation of L. sphaericus CBAM5 in An Alginate Matrix by Wet Electrospraying}

The bacteria suspension in MMS (90 mL) previously obtained (Section 2.1) was mixed with sodium alginate at $1 \% \mathrm{w} / \mathrm{v}$. The solution was placed in a $20 \mathrm{~mL}$ syringe which was connected to a flow pump and was wet electrosprayed for $5 \mathrm{~h}$ into a $\mathrm{CaCl}_{2} 2 \% \mathrm{w} / \mathrm{v}$ solution in a collector covered with aluminum foil using an EHP machine (Figure 1b). The process was conducted at room temperature, under a constant flow of $10 \mathrm{~mL} / \mathrm{h}$ using a 20-Gauge injector and scanning vertically onto the metallic collector. A dual polarization added voltage of $11.7 \mathrm{kV}$ and a tip-to-collector distance of $20 \mathrm{~cm}$ were used. The bacteria-containing microparticles were filtrated, washed with distilled water, and stored at $4{ }^{\circ} \mathrm{C}$ until further use.

In order to quantify the bacterial concentration, $0.5 \mathrm{~g}$ of microparticles were crushed and mixed by placing them with $0.5 \mathrm{~mL}$ of sterile saline solution $(0.85 \%)$ in a vortex. Standard serial 10 -fold 
dilutions were inoculated $(10 \mu \mathrm{L})$ in nutrient agar and incubated for $20 \mathrm{~h}$ at $30^{\circ} \mathrm{C}$ for the drop plate count method [19].

\subsection{Characterization of Electrospun and Electrosprayed Microstructures}

\subsubsection{Scanning Electron Microscopy (SEM) and Energy Dispersive X-Ray Spectroscopy (EDS) Analysis}

The micro-fibrous mats of PCL with and without immobilized bacteria were observed by scanning electron microscopy (SEM) using the JEOL JSM-6490LV (JEOL, Tokyo, Japan) scanning electron microscope equipped with an Oxford INCA PentaFetX3 energy dispersive X-ray spectroscopy (EDS) detector. Mats from the gold biosorption assays were also collected and sequentially washed with ethanol at $70 \%, 90 \%$, and $100 \%$. They were then placed in an aluminum support for metallization with graphite and SEM observation. A semi-quantification of gold with energy dispersive X-ray spectroscopy (EDS) was also performed. Estimation of the average fiber diameter was conducted by means of Image J software from 300 fibers at random from SEM images.

\subsubsection{Optical Microscopy}

The obtained microcapsules were observed using an optical microscope to measure the average diameter of the spheres. Several samples were placed in glass slides and observed in a light microscope Zeiss Axioskop 40 and different visual fields were photographed and analyzed by Image J to measure the diameter of the microcapsules.

\subsection{Gold Biosorption Assays with Electrospun and Electrosprayed Microstructures}

2.4.1. Biosorption by Inclusion of Micro-Fibrous Mats with Immobilized L. sphaericus CBAM5 in a Synthetic Water with Gold

For the biosorption assay, membranes with and without immobilized bacteria were placed in $30 \mathrm{~mL}$ of MSM spiked with $\mathrm{HAuCl}_{4} \times 3 \mathrm{H}_{2} \mathrm{O}(10 \mathrm{mg} / \mathrm{L})$. The mixture was incubated at $30{ }^{\circ} \mathrm{C}$ and $60 \mathrm{rpm}$. Aliquots of $1.5 \mathrm{~mL}$ were taken from the flasks at $0,2,4,18$, and $120 \mathrm{~h}$. Flame atomic absorption spectrometry (FAAS) was used to analyze the gold concentration in the supernatants as described below. The bioassay was conducted in triplicate.

The sorption capacities (Ss) of the PCL sub-micro-fibrous mats with and without bacteria were calculated by Equation (1):

$$
S s\left(\frac{m g}{g}\right)=\left(\frac{\left(C_{0}-C_{x}\right) V}{W}\right),
$$

where $C_{0}$ is the initial gold concentration $(\mathrm{mg} / \mathrm{L})$ in the supernatant, $C_{x}$ is the gold concentration in the aliquots taken at different times from the bioassay $(\mathrm{mg} / \mathrm{L}), \mathrm{V}$ is the volume used in the bioassay $(\mathrm{L})$, and $\mathrm{W}$ is the total PCL mat weight (g).

2.4.2. Gold Biosorption Performance of Micro-Fibrous Mats with Immobilized L. sphaericus CBAM5 in a Filtration System

PCL mats with immobilized bacteria were wet with saline solution $(0.85 \%)$ and then placed in a filtration system (MILLICUPTM-FLEX, Millipore). Then, $30 \mathrm{~mL}$ of MMS spiked with $10 \mathrm{ppm}$ of $\mathrm{HAuCl}_{4} \times 3 \mathrm{H}_{2} \mathrm{O}$ were dripped over the filtration system with a constant flow of $150 \mathrm{~mL} / \mathrm{h}$ (flow pump BYZ-810D) and gravity filtration was performed. The filtrate was collected, and 15 cycles of filtration were used. Aliquots of the filtrate were taken after 5, 10, and 15 cycles. Complete filtration time was $3 \mathrm{~h}$. Finally, FAAS was used to analyze the gold concentration in the aliquots as described below. The bioassay was conducted in triplicate. The sorption capacities (S) of the PCL sub-micro-fibrous mats with and without bacteria were calculated by Equation (1). 


\subsubsection{Biosorption of Gold by Microencapsulated Cells of L. sphaericus CBAM5 in Alginate}

This assay was developed as previously reported [17]. Briefly, $5 \mathrm{~g}$ of alginate microcapsules with L. sphaericus CBAM5 were added to $15 \mathrm{~mL}$ of MSM spiked with $\mathrm{HAuCl}_{4} \times 3 \mathrm{H}_{2} \mathrm{O}(60 \mathrm{mg} / \mathrm{L})$ in $50 \mathrm{~mL}$ flasks. The mixture was incubated at $30^{\circ} \mathrm{C}$ and $150 \mathrm{rpm}$. Aliquots of $1.5 \mathrm{~mL}$ were taken from the flasks at 0,2 , and $4 \mathrm{~h}$. FAAS was used to analyze the gold concentration in the supernatants as described below. The bioassay was conducted in triplicate.

The sorption capacities (S) of electrosprayed microcapsules with and without bacteria were calculated by Equation (2):

$$
S\left(\frac{m g}{g}\right)=\left(\frac{\left(C_{0}-C_{x}\right) V}{W}\right),
$$

where $C_{0}$ is the initial gold concentration $(\mathrm{mg} / \mathrm{L})$ in the supernatant, $C_{x}$ is the gold concentration in the aliquots taken at different times from the bioassay $(\mathrm{mg} / \mathrm{L}), \mathrm{V}$ is the volume used in the bioassay $(\mathrm{L})$, and $\mathrm{W}$ is the total microcapsules wet weight $(\mathrm{g})$.

\subsection{Flame Atomic Absorption Spectrometry (FAAS) Measurements}

All the experiments conducted to quantify gold were carried out using a High-Resolution Continuum Source Atomic absorption spectrometer (HR-CSAAS, ContrAa 800, commercially available from Analytik Jena, Jena, Germany) in flame mode (FAAS). Flame conditions were properly optimized before taking the measurements, using the absorption line at $242.7590 \mathrm{~nm}$. All gold standards were made on the day of measurement by diluting $1000 \mathrm{mg} / \mathrm{L}$ standard $\left(\mathrm{HAuCl}_{4}, \mathrm{CertiPUR}{ }^{\circledR}\right.$, Merck, $\mathrm{HCl}$ 2 mole/L, Darmstadt, Germany) to concentrations between 0.5 and $10 \mathrm{ppm}$. Distilled water and hydrochloric acid $1 \mathrm{~mol} / \mathrm{L}$ (ACS reagent, 37\%, Merck, Darmstadt, Germany) were used to acidify and dilute all standards and samples.

\subsection{Statistical Analysis}

Statistical analysis of biosorption data was performed through a Student's t-test to compare two groups of data at $p<0.05$. All the analyses were performed using Software R version 3.5.1.

\section{Results}

\subsection{Morphological Characterization of Electrospun and Electrosprayed Microstructures}

\subsubsection{Characterization of Electrospun Fibers with and without Immobilized L. sphaericus CBAM5}

The sub-micro-fibrous PCL mat was characterized by SEM analysis and its average diameter length and thickness were calculated. The average diameter obtained for the freshly synthesized PCL fibers was $3.5 \pm 1.1 \mu \mathrm{m}$ (Figure 2a) and this small value indicates that the mat has a large superficial area. Also, the fibers were randomly oriented over the collector and there was no evidence of pores formed in the mat.

The above characteristics of the PCL mat make it a suitable material for bacterial immobilization. This was proven by the determination of bacterial concentration immobilized using the detachment protocol. After the sonication of the PCL mats with bacteria, the concentration of L. sphaericus CBAM5 in saline solution was $5.59 \times 10^{7} \mathrm{CFU} / \mathrm{mL}$ for the first cycle and more than $1 \times 10^{6} \mathrm{CFU} / \mathrm{mL}$ after the second cycle. No significant differences were determined for the average diameter of the fibers after the bacterial immobilization. The final diameter was $4.72 \pm 1.64 \mu \mathrm{m}$ (Figure $2 \mathrm{~b}$ ). This shows that the inclusion of the mat in an aqueous medium does not affect its morphology. In addition, the SEM analysis showed the presence of bacteria attached to the PCL fibers as shown in Figure $2 b$. Finally, the average thickness of the mat after $3 \mathrm{~h}$ of PCL solution deposition by electrospinning was $66.34 \pm 16.08 \mu \mathrm{m}$. 


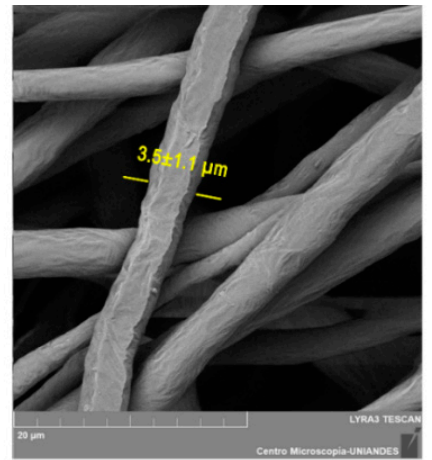

(a)

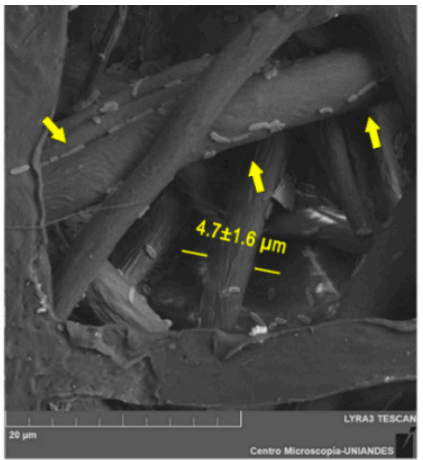

(b)

Figure 2. (a) Scanning electron microscopy (SEM) micrograph of a PCL membrane freshly synthesized (average diameter is $3.5 \pm 1.1 \mu \mathrm{m}$ ). (b) SEM micrograph of a PCL membrane with immobilized bacteria (average diameter is $4.72 \pm 1.64 \mu \mathrm{m}$ ).

\subsubsection{Characterization of Electrosprayed Microcapsules with L. sphaericus CBAM5}

The microcapsules obtained were observed using an optical microscope to measure the average diameter of the spheres. Figure 3 shows the measured diameter lengths and the average is $0.73 \pm$ $0.06 \mathrm{~mm}$, which is almost four times smaller than the diameter of capsules obtained by dripping the bacterial suspension with alginate over $\mathrm{CaCl}_{2}$ (data previously published, [17]). Moreover, the bacterial concentration in the microbeads was $1.17 \times 10^{6} \mathrm{CFU} / \mathrm{mL}$, demonstrating that no cell viability was lost after the exposure to high voltages during the electrospinning process.

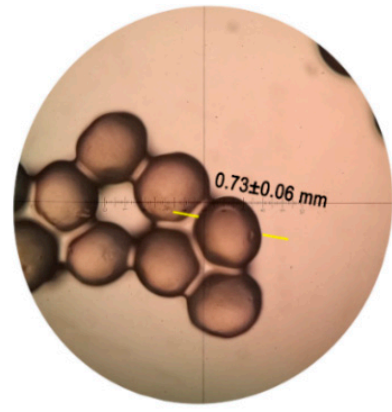

(a)

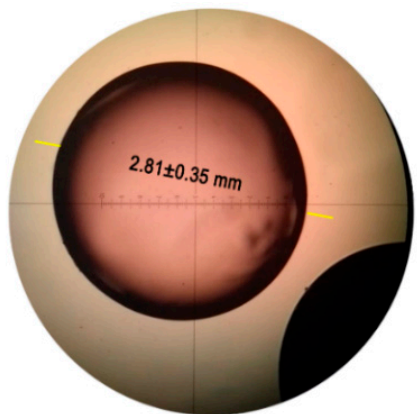

(b)

Figure 3. (a) Optical microscopy of the alginate microcapsules with L. sphaericus CBAM5 (average diameter is $0.73 \pm 0.06 \mathrm{~mm}$ ). (b) Optical microscopy of the dripped alginate capsules with L. sphaericus CBAM5 (average diameter is $2.81 \pm 0.35 \mathrm{~mm}$ ) [17].

\subsection{Gold Biosorption Assays with Electrospun and Electrosprayed Microstructures}

3.2.1. Biosorption of Gold by Inclusion of Micro-Fibrous Membranes with Immobilized L. sphaericus CBAM5

In order to assess the gold biosorption efficiency of L. sphaericus CBAM5 immobilized on a PCL membrane, FAAS was used to determine the gold concentration of the supernatant after the inclusion of the bio-composite mat in synthetic water with an initial concentration of $10 \mathrm{mg} / \mathrm{mL} \mathrm{HAuCl}{ }_{4} \times 3 \mathrm{H}_{2} \mathrm{O}$. As shown in Figure 4, the sorption capacity of the bio-composite electrospun mat was low and only $16 \%$ of gold was captured from the aqueous medium after $4 \mathrm{~h}$ of the bioassay and no gold removal was identified for the control assay. Immobilized L. sphaericus CBAM5 required a period of $120 \mathrm{~h}$ to remove $93 \%$ of the gold in the aqueous medium, while the neat PCL mat was able to remove $57 \%$ of the metal after that period of time. The difference between the biosorption efficiency of the bio-composite mat indicated that the presence of bacterial cells was responsible for the greatest proportion of gold capture. 


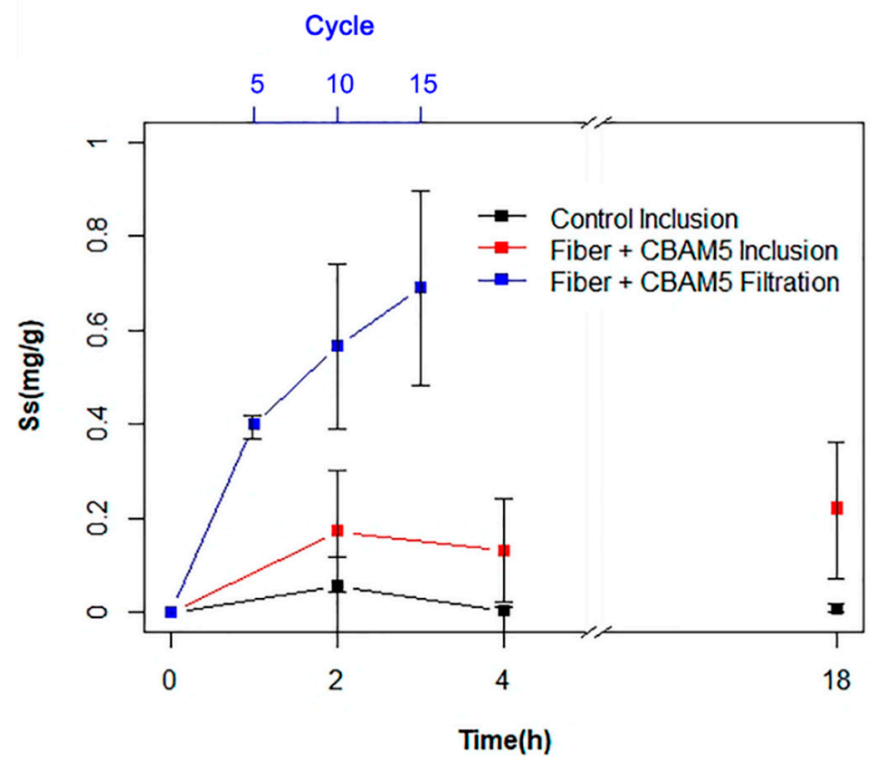

Figure 4. Gold (10 ppm) biosorption assays with L. sphaericus CBAM5 immobilized in PCL fibrous mats (Fiber + CBAM5) and the fiber without cells (Control) by inclusion in synthetic water and using a filtration system.

The removal of gold by the attached cells of L. sphaericus CBAM5 was also confirmed using SEM analysis. Figure 5 shows that the bacteria have a bacilli morphology typical of L. sphaericus CBAM5 and the EDS analysis showed that the biomass was able to accumulate gold.

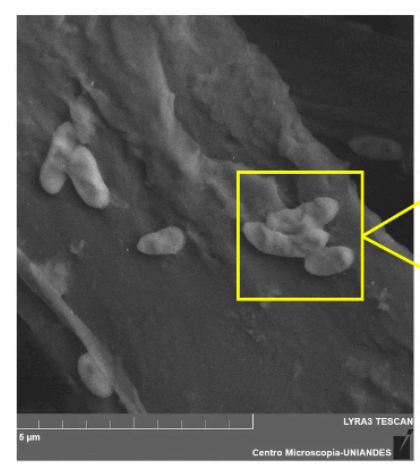

(a)

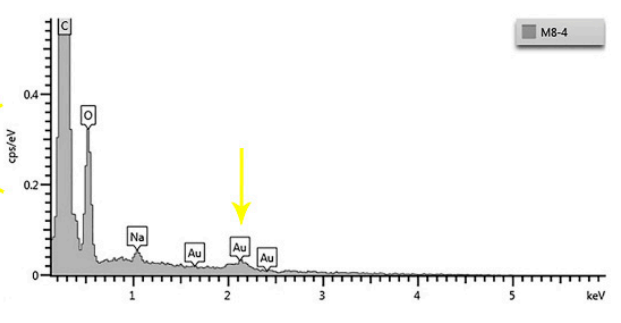

(b)

Figure 5. SEM micrographs of L. sphaericus CBAM5 cells (a) attached to a PCL microfiber seen with retro-dispersed electrons. (b) EDS analysis of image (a) showing the presence of Au in the cells.

3.2.2. Gold Biosorption Performance of Micro-Fibrous Membranes with Immobilized L. sphaericus CBAM5 in a Filtration System

A filtration system was set up and several cycles of filtration were performed as an attempt to improve the gold biosorption efficiency of the micro-fibrous PCL mat with L. sphaericus CBAM5. Figure 4 shows that the PCL mat with immobilized bacteria had a high sorption capacity and removed $51 \%$ of the gold from the liquid sample after 15 cycles of filtration, which took a total time of $3 \mathrm{~h}$. It is believed that greater efficiency could be achieved by performing more cycles.

It can thus be suggested that placing the PCL mat in a continuous filtration system can significantly improve the removal of gold from liquid media when compared to a process by which the membrane is submerged in the synthetic water sample. 


\subsubsection{Biosorption of Gold by Microencapsulated Cells of L. sphaericus CBAM5 in Alginate}

The efficiency of gold biosorption using the electrosprayed encapsulated bacteria in alginate was compared with the microcapsules free of L. sphaericus CBAM5. The results are presented in Figure 6 . It was determined that the presence of bacteria in the matrix enhanced the capture of gold from the aqueous media. Moreover, the mg of gold captured were corrected using the total amount of alginate beads used in the bioassays in order to compare this with data previously published where alginate capsules were obtained by dripping the bacterial suspension into the $\mathrm{CaCl}_{2}$ solution [17]. By using dripped alginate capsules with bacteria, an efficiency of $0.02 \mathrm{mg}$ of captured $\mathrm{Au} / \mathrm{g}$ wet material was achieved after $2 \mathrm{~h}$ of the bioassay. While with electrosprayed microcapsules, an efficiency of $0.04 \mathrm{mg}$ of captured $\mathrm{Au} / \mathrm{g}$ wet material was obtained. It can be said that the electrosprayed alginate beads showed a more rapid capture of gold than the dripped alginate beads with L. sphaericus CBAM5. Also, after $4 \mathrm{~h}$, the electrosprayed matrix captured almost doubled the amount of gold from the aqueous medium compared to the dripped alginate beads (data not shown).

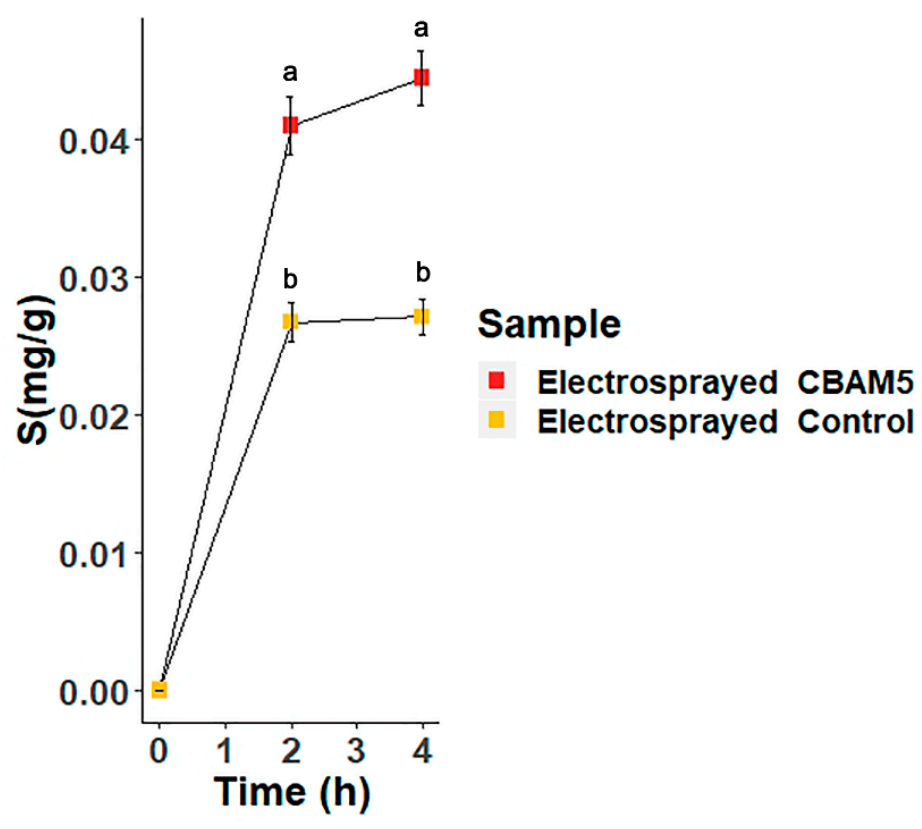

Figure 6. Gold Biosorption assay with L. sphaericus CBAM5 encapsulated in microcapsules of alginate (Electrosprayed CBAM5) and with microcapsules free of bacteria (Electrosprayed Control) for $4 \mathrm{~h}$. Points at 2 and $4 \mathrm{~h}$ denoted by a different letter differ significantly at $p<0.05$ according to a Student's t-test analysis.

\section{Discussion}

Several techniques have been proposed for the removal and recycling of metal ions from water bodies. Nevertheless, the use of sorption procedures with micro-structured materials is a suitable alternative to capture metal ions due to its high efficiencies, simple operation, and the flexibility of the materials used [2].

As such, two types of bio-composite micromaterials were developed in this study to enhance the gold biosorption efficiency of L. sphaericus CBAM5, a bacterium capable of binding with several metal ions such as $\mathrm{Hg}$ (II) [15] and $\mathrm{Au}(\mathrm{III})[16,17]$.

Firstly, PCL micro-fibrous mats were synthesized by using the electrospinning technique, which allowed the production of a sub-micro-scale structure with an average diameter of $3.5 \mu \mathrm{m}$, suitable for immobilization by adhesion of L. sphaericus CBAM5, as shown in Figure 2. Bacteria were immobilized by attachment to the randomly oriented fibers and due to their large superficial area [11]. An adsorption mechanism involving weak interactions like hydrogen bonds, hydrophobic bonds, or van der Waals 
interactions between the cells and the polymeric matrix occurred [20]. These weak interactions could lead to the release of bacteria from the membrane and these should be studied in the future.

After validating the high bacterial titers attached to the mats, an assay was performed to determine the gold biosorption efficiency of the bio-composites. The results of this study indicated that the capture of gold was a slow process (Figure 4 ) that required $120 \mathrm{~h}$ to remove $93 \%$ of the metal in solution. A possible explanation for this result may be the moderate wettability of the PCL polymeric structure due to its high hydrophobicity which restrains the water flux and thus, the contact of the solution with the bacteria immobilized [21].

Thus, a filtration system using the PCL mat was proposed in order to improve the efficiency of gold capture. Such a process allows a higher contact time of the solution with the membrane, and thus enables the immobilized bacteria and the PCL microstructure to interact and to efficiently adsorb gold ions in solution. In order to make a direct comparison between the efficiency of the two systems, the value of gold sorbed was corrected using the amount of PCL mats employed (g sorbed Au/g PCL). By doing this, a value of $0.56 \mathrm{~g}$ sorbed $\mathrm{Au} /(\mathrm{g}$ PCL) was determined for the membrane after 10 cycles of filtration and $0.17 \mathrm{~g}$ sorbed $\mathrm{Au} /(\mathrm{g}$ PCL) was found for the membrane submerged in the liquid sample for $2 \mathrm{~h}$. The efficiency of the filtration system is therefore approximately three-fold greater than that of the inclusion system.

$\mathrm{Li}$ et al. reported a gold adsorption capacity of approximately $2.5 \mathrm{mmol} / \mathrm{g}$ using thioamide-group chelating nanofibers of polyacrylonitrile after about $12 \mathrm{~h}$ of exposure to a gold solution [22]. This value is comparable to the sorption capacity obtained in this work $(2.8 \mathrm{mmol} / \mathrm{g})$ by using a filtration system with the PCL bio-composite mat. However, it is worth noting that the time required in this study was only $2 \mathrm{~h}$ and the process to obtain the material did not require high temperatures and it consumed less resources.

PCL micro-fibrous mats' high level of efficiency to capture gold may be explained by the fact that the morphology of the bio-composite brings several advantages during the sorption of gold from the aqueous medium, allowing it to capture the metal with or without immobilization with bacteria (Figures 4 and 5). Its sub-micro-structure offers a large surface-to-volume ratio that provides several active sites for bacterial adsorption or metal binding and this reduces the amounts of material required for the assays. Also, the porosity of the material and its interconnectivity allows the water to permeate through filtration systems applied for water treatment [5]. The microfibers with immobilized bacteria have higher selectivity and therefore restrict the flow of specific substances or elements such as gold ions and allow the flux of water.

L. sphaericus CBAM5 is responsible for the great efficiency as these living bacteria present active and passive mechanisms for gold removal, such as absorption and adsorption, respectively [14]. In the case of adsorption, it has previously been shown that this bacterium presents an S-Layer protein that assembles in the cell wall and acts as an ion trap [18]. Moreover, it is known that this protein possesses functional groups with affinity to metals like $\mathrm{Au}(\mathrm{III})$ and thus, complexation may occur after the exposure of L. sphaericus CBAM5 to that metal ion. This can be observed in Figure 5, where a SEM analysis demonstrated the presence of gold in the surface of the bacteria. In addition, metabolically active cells of $L$. sphaericus CBAM5 are able to transport metal ions through efflux pumps or ion channels [23] and accumulate gold inside the cell [16].

The other approach to enhance the gold biosorption of L. sphaericus CBAM5 involved the microencapsulation of the living cells in an alginate matrix using electrospraying. By using a high voltage during the injection of the bacterial suspension with alginate into a $\mathrm{CaCl}_{2}$ solution, a large decrease in the capsules' diameter was achieved and the resulting spheres were four times smaller than the ones obtained by dripping the alginate solution with no voltage supplied (Figure 3). Several properties of the injected solution, such as its conductivity due to the presence of ionic salts, favored the initiation of jetting and the formation of the Taylor cone, which is responsible for the decrease in the capsules diameter [24]. 
Notably, a high bacterial titer was determined in the microcapsules which shows that there was no considerable loss of cell viability after the exposure of the bacterial suspension to high voltage. These results demonstrated that the encapsulation in an alginate matrix acts as a protection layer for bacteria and it could also prevent their deterioration by factors such as low $\mathrm{pH}$, UV light, oxygen, drought, and other stress conditions in the environment [25].

The gold biosorption efficiency of the microcapsules with L. sphaericus CBAM5 was determined and compared with the performance of the capsules with a millimeter scale diameter. The microcapsules showed a more rapid sorption of gold from the aqueous medium. The observed increase in the biosorption efficiency by microcapsules could be attributed to their small size and large surface-to-volume ratio [24], which increase the effective retention time of the solution and its exposure to bacterial cells. As seen in Figure 6, the sorption of gold could be divided into two processes. First, a rapid step that involves the absorption of the solution by the porous structure of alginate and the ad/absorption of gold by the encapsulated bacteria, and second, a process that reaches equilibrium with the saturation of the bio-composite [26]. Nevertheless, this should be verified in future work through a kinetic study and by analyzing more aliquots at different points in time.

In order to make a comparison between the two polymers employed in this study, Equation (2) was used to determine the sorption capacity of the microcapsules but instead of using the wet weight of the material, the dry weight of the alginate microbeads with L. sphaericus CBAM5 was employed as this value is comparable to the sorption capacity (Ss) of the PCL sub-micro-fibrous mat with immobilized bacteria. As shown in Table 1, the PCL mat placed in a filtration system yielded a higher gold capture efficiency than the electrosprayed alginate microcapsules with L. sphaericus CBAM5. This could be attributed to the higher surface area per gram of polymer obtained for the PCL mat due to the smaller size of the fibers compared to the diameter of the alginate microcapsules. This higher surface area allows a better distribution of the bacteria in the material and their effective interaction with gold. Moreover, the exposure of the PCL mat to the gold solution for ten cycles allowed a better contact time of the bacteria to the metal ions, improving their sorption capacity compared to the efficiency obtained using a batch system with the alginate microcapsules.

Table 1. Comparison between the gold sorption efficiency of the PCL bio-composite mat and the alginate microcapsules with Lysinibacillus sphaericus CBAM5, after $2 \mathrm{~h}$ of the bioassays.

\begin{tabular}{ccc}
\hline Material & Size & Captured Au/(Weight Dry Material) \\
\hline PCL sub-micro-fibrous mat & (Inclusion) & $\mathbf{m g} / \mathbf{g}$ \\
$\begin{array}{c}\text { PCL sub-micro-fibrous mat } \\
\text { (Filtration) }\end{array}$ & $2.91 \pm 0.36$ & $0.17 \pm 0.13$ \\
Electrosprayed microcapsules & $730 \pm 60$ & $0.56 \pm 0.17$ \\
\hline
\end{tabular}

In conclusion, both micro-structured matrices were suitable for the immobilization and protection of L. sphaericus CBAM5, and they showed improved gold sorption performances so they could be applied to the recycling of this precious metal from industrial wastewaters, specially the PCL sub-micro-fibrous mats placed in a filtration system, as this showed the higher efficiency. Further research should be conducted to investigate the selectivity of both bio-composite materials by exposing them to a complex solution of metal ions and quantifying the sorption capacity of the micro-fibrous mats and microcapsules to each metal. Moreover, the recovery of gold from both micro-structured matrices should be studied using different desorption agents, such as thiourea. More efforts should be made to develop a scalable process in order to obtain larger amounts of these types of micro-structured-bio-composite materials.

Author Contributions: Conceptualization, C.P.-V., J.L.C.-M. and J.D.; Formal analysis, C.P.-V.; Funding acquisition, J.D.; Investigation, C.P.-V., J.L.C.-M. and J.D.; Methodology, C.P.-V., J.L.C.-M. and J.D.; Project administration, J.D.; Resources, J.L.C.-M. and J.D.; Supervision, J.L.C.-M. and J.D.; Validation, C.P.-V.; Visualization, C.P.-V.; 
Writing—original draft, C.P.-V.; Writing—review and editing, C.P.-V, J.L.C.-M. and J.D. All authors have read and agreed to the published version of the manuscript.

Funding: This research was funded by the Research Fund at the School of Science at Universidad de los Andes call 2019-1 for the Financing of Projects of Investigation and Participation in Academic Events Category Master Students, project code INV-2018-34-1265 and the Microbiological Research Center (CIMIC). APC was funded by School of Science at Universidad de los Andes and the Microbiological Research Center (CIMIC).

Acknowledgments: We would like to acknowledge Monica Beatriz López Santos for all her contributions and support at EDS-SEM analysis at Microscopy Center in Universidad de Los Andes. We would also like to thank Ricardo Rivas for the technical support required for the Flame atomic absorption spectrometry (FAAS) measurements in the Chemistry Department in the Universidad de Los Andes. We also thank Tiziana Laudato for the English grammar corrections provided.

Conflicts of Interest: The authors declare no conflict of interest. The funders had no role in the design of the study; in the collection, analyses, or interpretation of data; in the writing of the manuscript, or in the decision to publish the results.

\section{References}

1. Khin, M.M.; Nair, A.S.; Babu, V.J.; Murugan, R.; Ramakrishna, S. A review on nanomaterials for environmental remediation. Energy Environ. Sci. 2012, 5, 8075-8109. [CrossRef]

2. Wu, Y.; Pang, H.; Liu, Y.; Wang, X.; Yu, S.; Fu, D.; Chen, J.; Wang, X. Environmental remediation of heavy metal ions by novel-nanomaterials: A review. Environ. Pollut. 2019, 246, 608-620. [CrossRef]

3. Yeh, Y.C.; Creran, B.; Rotello, V.M. Gold nanoparticles: Preparation, properties, and applications in bionanotechnology. Nanoscale 2012, 4, 1871-1880. [CrossRef]

4. Echegoyen, Y.; Fabra, M.J.; Castro-Mayorga, J.L.; Cherpinski, A.; Lagaron, J.M. High throughput electro-hydrodynamic processing in food encapsulation and food packaging applications: Viewpoint. Trends Food Sci. Technol. 2017, 60, 71-79. [CrossRef]

5. Peng, S.; Jin, G.; Li, L.; Li, K.; Srinivasan, M.; Ramakrishna, S.; Chen, J. Multi-functional electrospun nanofibres for advances in tissue regeneration, energy conversion \& storage, and water treatment. Chem. Soc. Rev. 2016, $45,1225-1241$.

6. Santhosh, C.; Velmurugan, V.; Jacob, G.; Jeong, S.K.; Grace, A.N.; Bhatnagar, A. Role of nanomaterials in water treatment applications: A review. Chem. Eng. J. 2016, 306, 1116-1137. [CrossRef]

7. Woodruff, M.A.; Hutmacher, D.W. The return of a forgotten polymer-Polycaprolactone in the 21st century. Prog. Polym. Sci. 2010, 35, 1217-1256. [CrossRef]

8. Bashan, Y.; Hernandez, J.P.; Leyva, L.A.; Bacilio, M. Alginate microbeads as inoculant carriers for plant growth-promoting bacteria. Biol. Fertil. Soils 2002, 35, 359-368. [CrossRef]

9. Sarioglu, O.F.; San Keskin, N.O.; Celebioglu, A.; Tekinay, T.; Uyar, T. Bacteria immobilized electrospun polycaprolactone and polylactic acid fibrous webs for remediation of textile dyes in water. Chemosphere 2017, 184, 393-399. [CrossRef]

10. Oya, N.; Keskin, S.; Celebioglu, A.; Faruk, O.; Uyar, T. Encapsulation of living bacteria in electrospun cyclodextrin ultrathin fibers for bioremediation of heavy metals and reactive dye from wastewater. Colloids Surfaces B Biointerfaces 2018, 161, 169-176.

11. Sarioglu, O.F.; Celebioglu, A.; Tekinay, T.; Uyar, T. Evaluation of contact time and fiber morphology on bacterial immobilization for development of novel surfactant degrading nanofibrous webs. RSC Adv. 2015 5, 102750-102758. [CrossRef]

12. Tsuruta, T. Biosorption and recycling of gold using various microorganisms. J. Gen. Appl. Microbiol. 2004, 50, 221-228. [CrossRef]

13. Lozano, L.C.; Dussán, J. Metal tolerance and larvicidal activity of Lysinibacillus sphaericus. World J. Microbiol. Biotechnol. 2013, 29, 1383-1389. [CrossRef]

14. Velásquez, L.; Dussan, J. Biosorption and bioaccumulation of heavy metals on dead and living biomass of Bacillus sphaericus. J. Hazard. Mater. 2009, 167, 713-716. [CrossRef]

15. Vega-Páez, J.D.; Rivas, R.E.; Dussán-Garzón, J. High efficiency mercury sorption by dead biomass of Lysinibacillus sphaericus-new insights into the treatment of contaminated water. Materials 2019, 12, 1296. [CrossRef] 
16. Bustos, M.C.; Ibarra, H.; Dussán, J. The golden activity of Lysinibacillus sphaericus: New insights on gold accumulation and possible nanoparticles biosynthesis. Materials 2018, 11, 1587. [CrossRef]

17. Páez-Vélez, C.; Rivas, R.E.; Dussán, J. Enhanced Gold Biosorption of Lysinibacillus sphaericus CBAM5 by Encapsulation of Bacteria in an Alginate Matrix. Metals 2019, 9, 818. [CrossRef]

18. Peña-Montenegro, T.; Lozano, L.; Dussán, J. Genome sequence and description of the mosquitocidal and heavy metal tolerant strain Lysinibacillus sphaericus CBAM5. Stand. Genom. Sci. 2015, 10, 2-10. [CrossRef]

19. Naghili, H.; Tajik, H.; Mardani, K.; Razavi Rouhani, S.M.; Ehsani, A.; Zare, P. Validation of drop plate technique for bacterial enumeration by parametric and nonparametric tests. Vet. Res. Forum Int. Q. J. 2013, 4, 179-183.

20. Devi, S.A.; Harshiny, M. Role of Nanofibers in Bioremediation. In Bioremediation: Applications for Environmental Protection and Management; Springer: Singapore, 2018; pp. 99-114. ISBN 9789811074851.

21. Huang, L.; Arena, J.T.; Manickam, S.S.; Jiang, X.; Willis, B.G.; McCutcheon, J.R. Improved mechanical properties and hydrophilicity of electrospun nanofiber membranes for filtration applications by dopamine modification. J. Membr. Sci. 2014, 460, 241-249. [CrossRef]

22. Li, X.; Zhang, C.; Zhao, R.; Lu, X.; Xu, X.; Jia, X.; Wang, C.; Li, L. Efficient adsorption of gold ions from aqueous systems with thioamide-group chelating nanofiber membranes. Chem. Eng. J. 2013, 229, 420-428. [CrossRef]

23. Gómez-Garzón, C.; Hernández-Santana, A.; Dussan, J. A genome-scale metabolic reconstruction of Lysinibacillus sphaericus unveils unexploited biotechnological potentials. PLoS ONE 2017, 12, e0179666. [CrossRef] [PubMed]

24. García-Moreno, P.J.; Mendes, A.C.; Jacobsen, C.; Chronakis, I.S. Biopolymers for the Nano-microencapsulation of Bioactive Ingredients by Electrohydrodynamic Processing. In Polymers for Food Applications; Springer International Publishing AG: Berlin/Heidelberg, Germany, 2018; pp. 447-479. ISBN 9783319946252.

25. Covarrubias, S.A.; De-Bashan, L.E.; Moreno, M.; Bashan, Y. Alginate beads provide a beneficial physical barrier against native microorganisms in wastewater treated with immobilized bacteria and microalgae. Appl. Microbiol. Biotechnol. 2012, 93, 2669-2680. [CrossRef] [PubMed]

26. Hui, B.; Zhang, Y.; Ye, L. Preparation of PVA hydrogel beads and adsorption mechanism for advanced phosphate removal. Chem. Eng. J. 2014, 235, 207-214. [CrossRef] 